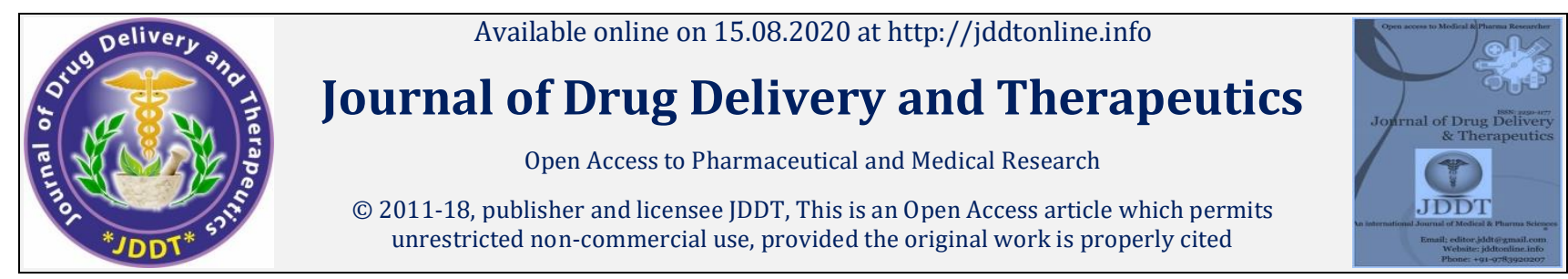

Open 1 Access

Research Article

\title{
Formulation development and evaluation of gastroretentive mucoadhesive tablets of glimepiride using natural polymers
}

\author{
Rahul Malasiya $^{1 *}$, Tarkeshwar P. Shukla ${ }^{2}$ \\ 1Student, Oriental College of Pharmacy, Bhopal, Madhya Pradesh, India \\ 2Professor, Oriental College of Pharmacy, Bhopal, Madhya Pradesh, India
}

\begin{abstract}
Glimepiride, a third-generation sulfonylurea is poorly soluble anti-diabetic drug. Currently, the use of natural gums and mucilage is of increasing importance in pharmaceutical formulations as valuable drug excipients. Natural plant-based materials are economic, free of side effects, biocompatible and biodegradable. The development of mucoadhesive sustained release drug delivery system is recommended in order to enhance the bioavailability. A mucoadhesive tablets were developed using the natural polymer sodium alginate and gum tragacanth. Mucoadhesion is a complex phenomenon which involves wetting, adsorption and interpenetration of polymer chains. The tablets of glimepiride were prepared by direct compression method. Pre-compression parameters were evaluated. The tablets were evaluated for post-compression parameters such as thickness, hardness, average weight, friability and In vitro release studies. All the compositions were resulted in adequate pharmacopoeia limits. The varying concentration of polymers was found to affect on in-vitro drug release and mucoadhesive strength. In vitro drug release of gastro retentive tablet of glimepiride shown that the formulation F5 was found to be the best formulation as it releases $98.78 \%$ Glimepiride in a sustain release manner for an extended period of time (up to $12 \mathrm{hrs}$ ). The release data was fitted to various mathematical models such as higuchi, korsmeyer-peppas, first order and zero order to evaluate the kinetics and mechanism of the drug release.Prepared tablets of glimepiride may prove to be a potential candidate for safe and effective controlled drug delivery over an extended period of time for gastro retentive drug delivery system.
\end{abstract}

Keywords: Glimepiride, Gastro retentive, Anti-diabetic drug, Direct compression method

Article Info: Received 17 June 2020; Review Completed 22 July 2020; Accepted 29 July 2020; Available online 15 August 2020

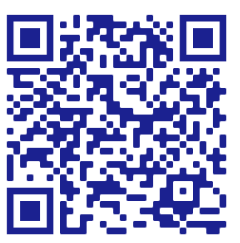

\section{Cite this article as:}

Malasiya R, Shukla TP, Formulation development and evaluation of gastroretentive mucoadhesive tablets of glimepiride using natural polymers, Journal of Drug Delivery and Therapeutics. 2020; 10 (4-s):153-159

http://dx.doi.org/10.22270/jddt.v10i4-s.4264

Rahul Malasiya, Oriental College of Pharmacy, Bhopal, Madhya Pradesh, India

\section{INTRODUCTION}

The last two decades mucoadhesion has become of interest for its potential to optimize localized drug delivery, by retaining a dosage form at the site of action (e.g. within the gastrointestinal tract) or systemic delivery by retaining a formulation in intimate contact with the absorption site (e.g. buccal cavity) as mucosal membranes ${ }^{1}$. Mucoadhesive drug delivery systems have so far not reached their full potential in oral drug delivery, because the adhesion of drug delivery systems in the GI tract is insufficient to provide a prolonged residence time of delivery systems in the stomach or small intestine ${ }^{2}$. Adhesion of bioadhesive drug delivery devices to the mucosal tissue offers the possibility of creating an intimate andprolonged contact at the site of administration ${ }^{3}$. Mucoadhesion and bioadhesion involves two materials in which at least one is biological in nature, held together for an extended period of time by interfacial forces. Alternately it is defined as the ability of a material (synthetic or biological) to adhere to a biological tissue for an extended period of time. Bioadhesion involves adhesion of the polymer with the biological membrane while mucoadhesion involves adhesion of the polymer with the mucus membrane. Adhesion as a process is simply defined as the "fixing" of two surfaces to one another ${ }^{4}$. Gastroretentive systems can remain in the gastric region for several hours and hence can significantly prolong the gastric residence time of drugs. Prolong gastric retention improves bioavailability, reduces drug wastage, and improves solubility for the drugs that are less soluble in the high $\mathrm{pH}$ environment ${ }^{5}$. Glimepiride is an oral blood glucose lowering drug belonging to the third generation sulphonylurea class that is currently available for treating hyperglycemia in non insulin dependent diabetes mellitus (NIDDM). Glimepiride is classified under class II according to biopharmaceutical classification systems 6 . Chemically glimepiride is identified as 1-[[p-[2-(3-ethyl-4-methyl-2-oxo3- pyrroline-1carboxamido) ethyl] phenyl] sulfonyl]-3(trans4-methylcyclohexyl) urea ${ }^{7}$. It is practically insoluble in water having high cell permeability ${ }^{8}$. It is slightly soluble in methanol and showed favorable partition coefficients (1.8 in octanol/pH7.4buffer) ${ }^{9}$. The primary mechanism of action of 
glimepiride in lowering blood glucose appears to be dependent on stimulating the release of insulin from the functioning pancreatic beta cells 10. Metformin and glimepiride tablets simultaneously targets insulin resistance and insulin deficiency in type 2 diabetes, which may account for the greater effects on hyperglycemia ${ }^{11}$.In recent years, natural polymers are growing rapidly and it continues to remain and important in the new formulation development of the controlled released dosage form ${ }^{12}$. Natural polymers are much safer than synthetic. They provide many applications in the formulation development of a new controlled release dosage form, such as binder, disintegrator, diluents and release modifier ${ }^{13}$.Therefore, they needs a novel approach to enhance the use of natural polymers in the formulation development of controlled released dosage form, because of the ease availability at an affordable price, high safety margin and higher productivity. Hence, the present study is aimed to enhance the use of natural plant based polymer as a release modifier to develop Glimepiride gastroretentive mucoadhesivetablet. The purpose of this study is to investigate the sustain release properties of gum tragacanth. These polymers were used as modifier using model drug glimepiride ${ }^{14}$.

\section{MATERIALS AND METHODS}

\section{Materials}

Glimepiride were obtained as pure sample from $\mathrm{m}$ Dr. Reddy's Laboratories, Hyderabad, India as gift samples along with their analytical reports. MCC was obtained from Mapromax, Life sciences Pvt. Ltd. Dehradun. Sodium alginate, gum tragacanth and Talc were purchased from SD Fine Chem. Limited, Mumbai. Magnesium stearate was purchased from LobaChemie Pvt. Ltd, Mumbai. All other chemical were purchased from Hi Media, Mumbai. Double distilled water was prepared freshly and used whenever required. All other chemicals used in this study including those stated were of analytical reagent (A.R.) grade.

\section{Determination of absorption maxima}

A solution of containing the concentration $10 \mu \mathrm{g} / \mathrm{ml}$ was prepared in $0.1 \mathrm{~N} \mathrm{HCl}$. UV spectrum was taken using Double beam UV/VIS spectrophotometer (Labindia-3000+). The solution was scanned in the range of $200-400 \mathrm{~nm}$.

\section{FT- IR Study}

FT- IR spectrum is an important record which gives sufficient information about the structure of a compound. This technique provides a spectrum containing a large number of absorption band from which a wealth of information can be derived about the structure of an organic compound. Identification of Glimepiride was done by FTIR Spectroscopy. It was identified from the result of IR spectrum as per specification.

\section{Preparation calibration curve}

$10 \mathrm{mg}$ of drug was accurately weighed and dissolved in $10 \mathrm{ml}$ $0.1 \mathrm{~N} \mathrm{HCl}$ in $10 \mathrm{ml}$ volumetric flask, to make $(1000 \mu \mathrm{g} / \mathrm{ml})$ standard stock solution (1). Then $1 \mathrm{ml}$ stock solution (1) was taken in another $10 \mathrm{ml}$ volumetric flask to make $(100 \mu \mathrm{g} / \mathrm{ml})$ sub stock solution (2), and then final concentrations were prepared $5-25 \mu \mathrm{g} / \mathrm{ml}$ with $0.1 \mathrm{~N} \mathrm{HCl}$. The absorbance of standard solution was determined using UV/ VIS spectrophotometer (Labindia $3000+$ ) at $232.0 \mathrm{~nm}$. Linearity of standard curve was assessed from the square of correlation coefficient $\left(\mathrm{r}^{2}\right)$ which determined by least-square linear regression analysis.

\section{Method for preparation of glimepiride mucoadhesive matrix tablet}

Direct compression was taken after to manufacture the mucoadhesive tablets of glimepiride ${ }^{15}$. Six different formulations (F1, F2, F3, F4, F5 and F6) were set up by direct compression. Every one of the polymers chose, drug and excipients were gone through strainer no. 40 preceding utilizing into plan. The sum and proportion of drug and polymers were weighed according to given in table 1 and all the definition were utilized for encourage assessments parameters.

\section{Pre compression evaluation}

Flow properties and compressibility properties of powder mixture were evaluated by measurement of angle of repose, bulk density, tapped density, carr's index and hausner's ratio.

\section{Angle of repose ( $\theta)$}

The angle of repose was determined by using fixed funnel method. The physical mixtures of drug with different excipients were prepared and the accurately weighed drug powder or its physical mixture was taken in a funnel. The height of the funnel was adjusted in such a way that the tip of the funnel just touches the apex of the heap of the drug powder. The powder was allowed to flow through the funnel freely onto surface. The angle of repose was calculated using the following equation.

$$
\theta=\tan -1(\mathrm{~h} / \mathrm{r})
$$

Where, $\mathrm{h}$ and $\mathrm{r}$ are the height and radius of the powder cone respectively.

\section{Bulk density}

Both loose bulk density (LBD) and tapped density (TBD) were determined were calculated using the following formulas.

$$
\begin{aligned}
& \text { LBD }=\text { Powder weight/volume of the packing } \\
& \text { TBD }=\text { Powder weight /tapped volume of the packing }
\end{aligned}
$$

\section{Compressibility index}

The compressibility index of the granules was determined by Carr's compressibility index.

$$
\text { Carr's index }(\%)=[(\mathrm{TBD}-\mathrm{LBD}) / \mathrm{TBD}] \times 100 \text {. }
$$

\section{Hausner's ratio}

Hausner's ratio is an indirect index of ease of measuring the powder flow. It was calculated by the following formula 16-18.

$$
\text { Hausner's ratio }=\text { Tapped density } / \text { Bulk density } \text {. }
$$

\section{Evaluation of tablets}

All the tablets were evaluated for following various parameters which includes 19,20.

\section{General Appearance}

Five tablets from various batches were randomly selected and organoleptic properties such as color, odor, taste, shape, were evaluated. Appearance was judged visually. Very good $(+++)$, good $(++)$, fair $(+)$ poor $(-)$, very poor $(--)$.

\section{Thickness and diameter}

Thickness and diameter of tablets were determined using Vernier caliper. Five tablets from each batch were used, and an average value was calculated. 


\section{Drug content}

Twenty tablets were taken and amount of drug present in each tablet was determined. The tablets were crushed in a mortar and the powder equivalent to $10 \mathrm{mg}$ of drug was transferred to $10 \mathrm{ml}$ standard flask. The powder was dissolved in $5 \mathrm{ml}$ of $0.1 \mathrm{~N} \mathrm{HCl}$ and made up to volume with of $0.1 \mathrm{~N} \mathrm{HCl}$. The sample was mixed thoroughly and filtered through a $0.45 \mu$ membrane filter. The filtered solution was diluted suitably and for drug content by UV spectrophotometer at $\lambda$ max of $232 \mathrm{~nm}$ using $0.1 \mathrm{~N} \mathrm{HCl}$ blank.

\section{Hardness}

For each formulation the hardness of five tablets was resolved utilizing the Monsanto hardness tester (Cadmach).

\section{Friability}

The friability of sample of 10 tablets was estimated utilizing a friability tester (Electro Lab). Ten tablets were weighed, rotated at $25 \mathrm{rpm}$ for 4 minutes. Tablets were reweighed after removal of fines (dedusted) and the percentage of weight loss was calculated.

\section{Uniformity of weight}

Twenty tablets were randomly selected from each batch individually weighed, the average weight and standard deviation of 20 tablets was calculated.

\section{Swelling index}

Swelling study of individual polymers and combinations was carried out using eight-stage USP type 1 (basket) Dissolution Test Apparatus (Lab India, DS 8000) at $50 \mathrm{rpm}$, and $0.1 \mathrm{~N} \mathrm{HCl}$ was used as medium, and the temperature was maintained at $37 \pm 0.5^{\circ} \mathrm{C}$. Weight of individual tablet was taken prior to the swelling study $\left(\mathrm{W}_{1}\right)$. The tablet was kept in a basket. The weight of tablet was taken at time interval of 2, 4, 8, 12 hours $\left(\mathrm{W}_{2}\right)^{21}$. Percent hydration (swelling index) was calculated using the following formula:

$$
\text { Swelling index }=\left(\mathrm{W}_{2}-\mathrm{W}_{1}\right) \times 100 / \mathrm{W}_{2}
$$

Where $W_{1}$ is the initial weight of tablet and $W_{2}$ is the weight of hydrated tablet.

\section{Determination of mucoadhesive strength}

The working of a double beam physical balance formed the basis of the bioadhesion test assembly. The left pan was removed and hung with a stainless steel chain. A Teflon block with 1.5 in height and 1.5 in diameter was hung with the stainless steel chain to balance the weight of the other pan. The height of the total set up was adjusted to accommodate a glass container or beaker below it leaving a head space of about $0.5 \mathrm{~cm}$ in between. Block of 2 in height and 1.5 in diameter was kept inside the glass vessel, which was then positioned below the top hung Teflon block. Suitable weights were added on the right pan to balance the beam of the balance. The porcine gastric mucosa was attached with the mucosal side upward onto the lower Teflon block which was then placed in the glass vessel. Sufficient simulated gastric fluid was filled into the beaker so that the surface of the fluid just touches the mucosal surface to Teflon block. A tablet was fixed to the bottom portion of the cylindrical shaped base with 'feviquick' glue. The string with tablet was hung in such a way that the tablet was just in contact with the surface of the mucosal side of pig stomach when the balance was in a balanced position. The balance was left in a balanced position for fixed time of 5 minutes and then slowly weights were increased on the right pan until the tablet detaches from the surface of the intestinal mucosa. The weights on right side pan gave the mucoadhesive strength of the tablet in grams. From mucoadhesive strength, the bioadhesion force was calculated per unit area of the tablet as follows.

$$
F=\frac{W w \times G}{1000 \times A}
$$

Where $\mathrm{F}$ is the bioadhesion force $\left(\mathrm{kg} / \mathrm{m} / \mathrm{s}^{2}\right), \mathrm{Ww}$ is the mass applied $(\mathrm{g}), \mathrm{g}$ is the acceleration due to gravity $\left(\mathrm{cm} / \mathrm{s}^{2}\right)$ and $\mathrm{A}$ is the surface area of the patch $\left(\mathrm{cm}^{2}\right)$.

\section{Dissolution rate studies}

In vitro drug release of the sample was done using USP-type II dissolution apparatus (Paddle type). The dissolution medium, $900 \mathrm{ml} 0.1 \mathrm{~N} \mathrm{HCl}$ was set into the dissolution flask maintaining the temperature of $37 \pm 0.5^{\circ} \mathrm{C}$ and rpm of 75 . One tablet was set in every container of dissolution apparatus. The mechanical assembly was permitted to keep running for 10 hours. Sample measuring $5 \mathrm{ml}$ were pulled back after each 1 hour up to 2 hours using $10 \mathrm{ml}$ pipette. The new disintegration medium $\left(37^{\circ} \mathrm{C}\right)$ was supplanted each time with a similar amount of the sample and takes the absorbance at $232 \mathrm{~nm}$ using spectroscopy 22-26.

Mathematical treatment of in-vitro release data: The quantitative analysis of the qualities got in dissolution/release tests is simpler when mathematical formulas that express the dissolution comes about as an element of a portion of the measurement frames attributes are utilized.

1. Zero-order kinetics: The pharmaceutical dosage frames following this profile release a similar measure of medication by unit of time and it is the ideal method of medication release keeping in mind the end goal to accomplish a pharmacological prolonged action. The following relation can, in a simple way, express this model:

$$
Q_{t}=Q_{0}+K_{o} t
$$

Where $Q_{t}$ is the amount of drug dissolved in time $t, Q_{o}$ is the initial amount of drug in the solution (most times, $Q_{0}=0$ ) and $\mathrm{K}_{\mathrm{o}}$ is the zero order release constant.

2. First-order kinetics: The following relation expresses this model:

$$
\log Q_{t}=\log Q_{0}+\frac{K_{1} t}{2.303}
$$

Where $\mathrm{Q}_{\mathrm{t}}$ is the amount of drug dissolved in time $\mathrm{t}, \mathrm{Q}_{\mathrm{o}}$ is the initial amount of drug in the solution and $\mathrm{K}_{1}$ is the zero order release constant.

Along these lines a graphic of the decimal logarithm of the released measure of drug versus time will be linear. The pharmaceutical dosage shapes following this dissolution profile, for example, those containing water-solvent drugs in permeable frameworks, discharge drug in a way that is corresponding to the measure of drug staying in its inside, in such way, that the measure of drug released by unit of time reduce.

3. Higuchi model: Higuchi built up a few theoretical models to ponder the arrival of water-solvent and low dissolvable medications in semi-strong or potentially strong grids. Mathematical expressions were acquired for sedate particles scattered in a uniform grid acting as the diffusion media.The simplified Higuchi model is expressed as:

$$
\mathrm{Q}=\mathbf{K}_{\mathbf{H}} \cdot \mathbf{t}^{\mathbf{1} / \mathbf{2}}
$$

Where $Q$ is the amount of drug released in time $t$ and $K_{H}$ is the Higuchi dissolution constant. Higuchi model describes drug release as a diffusion process based in the Fick's law, square root time dependent. This relation can be utilized to 
portray the drug dissolution from a few kinds of modified release pharmaceutical dosage structures, for example, transdermal systems and mucoadhesivetablets with waterdissolvable drugs.

4. Korsmeyer-Peppas model: Korsmeyer et al. used a simple empirical equation to describe general solute release behaviour from controlled release polymer matrices:

$$
\frac{M_{4}}{M_{\mathbf{m}}}=\mathbf{a} \mathbf{t}^{n}
$$

Where $M_{t} / M_{\infty}$ is fraction of drug released, a is kinetic constant, $\mathrm{t}$ is release time and $\mathrm{n}$ is the diffusional exponent for drug release. ' $n$ ' is the slope value of $\log M_{t} / M_{\infty}$ versus $\log$ time curve. Peppas stated that the above equation could adequately describe the release of solutes from slabs, spheres, cylinders and discs, regardless of the release mechanism. Peppas used this $n$ value in order to characterize different release mechanisms, concluding for values for a slab, of $n=0.5$ for fickian diffusion and higher values of $n$, between 0.5 and 1.0, or $n=1.0$, for mass transfer following a non-fickian model. In case of a cylinder $n=0.45$ instead of 0.5 , and 0.89 instead of 1.0 . This equation can only be used in systems with a drug diffusion coefficient fairly concentration independent. To the determination of the exponent $n$ the portion of the release curve where $\mathrm{M}_{\mathrm{t}} / \mathrm{M}_{\infty}<0.6$ should only be used. To use this equation it is also necessary that release occurs in a one-dimensional way and that the system widththickness or length-thickness relation be at least 10 . A modified form of this equation was developed to accommodate the lag time $(I)$ in the beginning of the drug release from the pharmaceutical dosage form:

$$
\frac{\mathbf{M}_{\mathbf{H}-l}}{\mathbf{M}_{\mathbf{w}}}=\mathbf{a}(\mathbf{t}-l)^{n}
$$

When there is the possibility of a burst effect, $b$, this equation becomes:

$$
\frac{M_{\mathbf{t}}}{M_{\mathbf{w}}}=\mathbf{a t}+\mathbf{b}
$$

In the absence of lag time or burst effect, 1 and bvalue would be zero and only at ${ }^{n}$ is used. This mathematical model, also known as Power Law, has been used very frequently to describe release from several different pharmaceutical modified release dosage forms.

\section{RESULTS AND DISCUSSION}

$\lambda_{\max }$ of glimepiride was found to be $232 \mathrm{~nm}$ by using U.V. spectrophotometer (Labindia-3000+) in linearity range 5$25 \mu \mathrm{g} / \mathrm{ml} \mathrm{Fig.1.} \mathrm{The} \mathrm{melting} \mathrm{point} \mathrm{of} \mathrm{glimepiride} \mathrm{was} \mathrm{205-}$ $207^{\circ} \mathrm{C}$ and Ft-IR spectra of pure drug shown in fig.2.

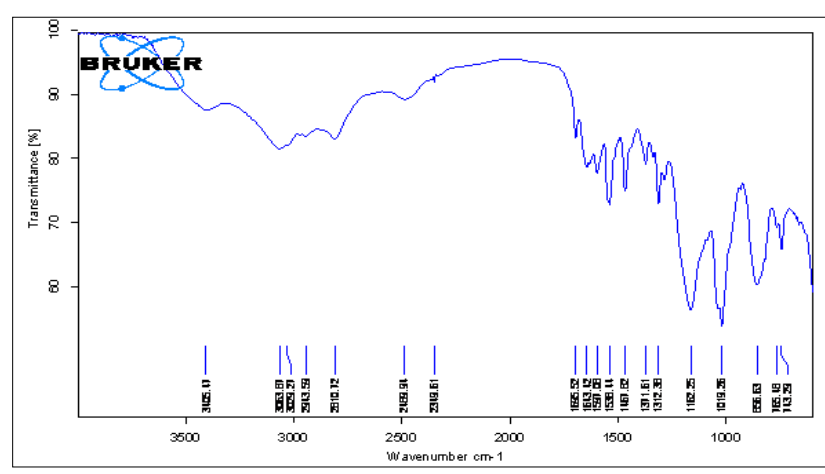

Figure 2: FT-IR spectra of pure Glimepiride

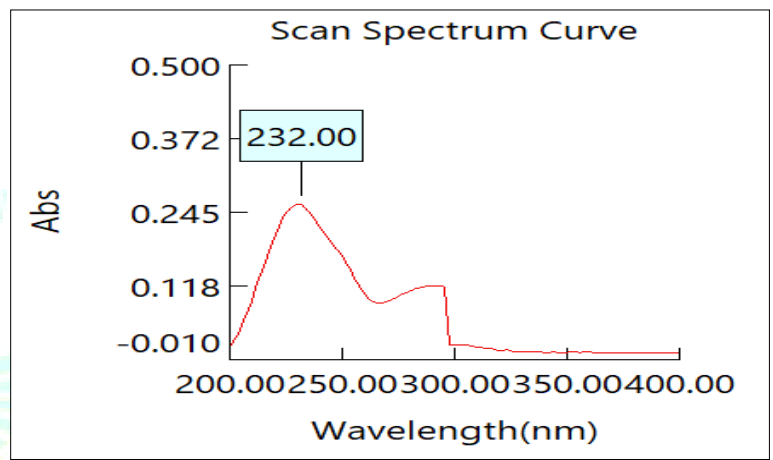

Figure 1: Determination of $\lambda_{\max }$ of Glimepiride

Tablet powder blend was subjected to various precompression parameters Table 2 . The bulk density of all the formulations was found to be in the range of 0.421to 0.457 $(\mathrm{gm} / \mathrm{ml})$ showing that the powder has good flow properties. The tapped density of all the formulations was found to be in the range of 0.525 to 0.562 showing the powder has good flow properties. The compressibility index of all the formulations was found to be ranging between 18.683to 19.810which shows that the powder has good flow properties. All the formulations have shown the Hauser's ratio ranging between 1.230 to 1.247 indicating the powder has good flow properties.

Table 1: Result of pre-compression properties of glimepiride

\begin{tabular}{|c|c|c|c|c|}
\hline F. Code & Bulk density(gm/ml) & Tapped density(gm/ml) & Compressibility index & Hausner's ratio \\
\hline F1 & 0.421 & 0.525 & 19.810 & 1.247 \\
\hline F2 & 0.422 & 0.526 & 19.772 & 1.246 \\
\hline F3 & 0.436 & 0.538 & 18.959 & 1.234 \\
\hline F4 & 0.452 & 0.558 & 18.996 & 1.235 \\
\hline F5 & 0.457 & 0.562 & 18.683 & 1.230 \\
\hline F6 & 0.442 & 0.551 & 19.782 & 1.247 \\
\hline
\end{tabular}

The results of post-compression parameters such as the uniformity of weight, hardness, thickness, friability, and drug content of the tablets are given in Table 3 . All the tablets of different batches complied with the official requirements of uniformity of weight. The hardness of the tablets ranged from $4.9 \pm 0.2$ to $5.2 \pm 0.1 \mathrm{~kg} / \mathrm{cm}^{2}$ and the friability values were ISSN: $2250-1177$ less than $0.9 \%$ indicating that the matrix tablets were compact and hard. The thickness of the tablets ranged from $2.1 \pm 0.1$ to $2.2 \pm 0.1 \mathrm{~mm}$. All the formulations satisfied the content of the drug as they contained $98.69 \pm 0.32$ to $99.56 \pm 0.45 \%$ of glimepiride and good uniformity in drug content was observed. Thus all the physical attributes of the 
prepared tablets were found be practically within control. In the present study 6 formulations with variable concentration of polymers (MCC, sodium alginate, gum tragacanth and gaur gum) were prepared by direct compression method and evaluated for physicochemical properties. The results of swelling index, and bioadhesion strength were given in Table 4, 5. The tablets were evaluated for in vitro dissolution studies in $0.1 \mathrm{~N} \mathrm{HCl}$ for 12 hours. The results of in-vitro drug release revealed that the glimepiride was released in a controlled manner from all the formulations where formulation F5 showed maximum drug release i.e. $98.78 \%$ at the end of $12^{\text {th }}$ hour. The results of release studies of formulations F1 to F6 are shown in Table 6 and Figure 3. The in vitro drug release data of the optimized formulation F5 was subjected to goodness of fit test by linear regression analysis according to zero order, first order kinetic equation, Higuchi's and Korsmeyer's models in order to determine the mechanism of drug release. When the regression coefficient values of were compared, it was observed that ' $r$ ' values of Peppas model was maximum i.e. 0.979 hence indicating drug release from formulations was found to follow Peppas order kinetics Table 7, 8 \& Fig. 4-7.

Table 2: Results of post compression properties of glimepiride matrix tablets

\begin{tabular}{|c|c|c|c|c|c|}
\hline $\begin{array}{c}\text { Formulation } \\
\text { code }\end{array}$ & $\begin{array}{l}\text { Thickness* } \\
\text { (mm) }\end{array}$ & $\begin{array}{c}\text { Hardness } \\
(\mathrm{kg} / \mathrm{cm} 2) \mathrm{n}=3\end{array}$ & $\begin{array}{c}\text { Weight variation (mg) } \\
n=3\end{array}$ & $\begin{array}{c}\text { Friability (\%) } \\
n=3\end{array}$ & $\begin{array}{c}\text { Drug content (\%) } \\
n=3\end{array}$ \\
\hline $\mathrm{F} 1$ & $2.1 \pm 0.1$ & $5.1 \pm 0.2$ & $149 \pm 4$ & $0.852 \pm 0.008$ & $98.85 \pm 0.35$ \\
\hline F2 & $2.2 \pm 0.1$ & $5.2 \pm 0.1$ & $155 \pm 5$ & $0.845 \pm 0.007$ & $99.45 \pm 0.35$ \\
\hline F3 & $2.1 \pm 0.2$ & $5.1 \pm 0.1$ & $150 \pm 4$ & $0.825 \pm 0.004$ & $99.56 \pm 0.45$ \\
\hline F4 & $2.2 \pm 0.1$ & $4.9 \pm 0.2$ & $152 \pm 3$ & $0.785 \pm 0.008$ & $98.74 \pm 0.85$ \\
\hline F5 & $2.2 \pm 0.2$ & $5.1 \pm 0.2$ & $153 \pm 4$ & $0.658 \pm 0.009$ & $98.85 \pm 0.65$ \\
\hline F6 & $2.2 \pm 0.1$ & $5.2 \pm 0.3$ & $148 \pm 5$ & $0.785 \pm 0.007$ & $98.69 \pm 0.32$ \\
\hline
\end{tabular}

Table 3: Results of Swelling Index of glimepiride matrix tablets

\begin{tabular}{|c|c|c|c|c|}
\hline \multirow{2}{*}{ Formulation Code } & \multicolumn{4}{|c|}{ \% Swelling Index } \\
\cline { 2 - 5 } & $\mathbf{2}$ hrs. & 4 hrs. & 8hrs. & 12hrs. \\
\hline F1 & 20.23 & 45.65 & 64.56 & 73.25 \\
\hline F2 & 23.32 & 46.65 & 68.85 & 75.65 \\
\hline F3 & 24.56 & 47.78 & 65.56 & 74.58 \\
\hline F4 & 28.56 & 52.23 & 67.78 & 79.85 \\
\hline F5 & 26.65 & 50.45 & 69.98 & 80.21 \\
\hline F6 & 28.56 & 53.14 & 68.85 & 78.25 \\
\hline
\end{tabular}

Table 4: Results of determination of bioadhesionstrength

\begin{tabular}{|c|c|c|}
\hline S. No. & Formulation Code & Force of Adhesion \\
\hline $\mathbf{1 .}$ & F1 & 0.62 \\
\hline $\mathbf{2 .}$ & F2 & 0.65 \\
\hline $\mathbf{3 .}$ & F3 & 0.70 \\
\hline $\mathbf{4 .}$ & F4 & 0.48 \\
\hline $\mathbf{5 .}$ & F5 & 0.72 \\
\hline $\mathbf{6 .}$ & F6 & 0.65 \\
\hline $\mathbf{7 .}$ & F7 & 0.68 \\
\hline $\mathbf{8 .}$ & F8 & 0.74 \\
\hline $\mathbf{9 .}$ & F9 & 0.85 \\
\hline
\end{tabular}

Table 5: In-vitro drug release study of matrix tablets

\begin{tabular}{|c|c|c|c|c|c|c|}
\hline Time & \multicolumn{9}{|c|}{ \% Cumulative Drug Release } \\
\hline (hr) & F1 & F2 & F3 & F4 & F5 & F6 \\
\hline 0.5 & 45.56 & 42.23 & 40.27 & 38.98 & 35.56 & 30.33 \\
\hline 1 & 65.85 & 56.69 & 53.23 & 42.32 & 40.23 & 36.65 \\
\hline 1.5 & 78.89 & 71.32 & 69.98 & 55.65 & 45.65 & 40.23 \\
\hline 2 & 98.89 & 89.98 & 75.56 & 69.98 & 52.32 & 45.65 \\
\hline 3 & - & 98.65 & 86.65 & 81.12 & 65.85 & 50.65 \\
\hline 4 & - & - & 97.78 & 89.98 & 73.32 & 57.78 \\
\hline 6 & - & - & - & 98.89 & 79.98 & 63.32 \\
\hline 8 & - & - & - & - & 84.65 & 72.23 \\
\hline 12 & - & - & - & - & 98.78 & 75.65 \\
\hline
\end{tabular}




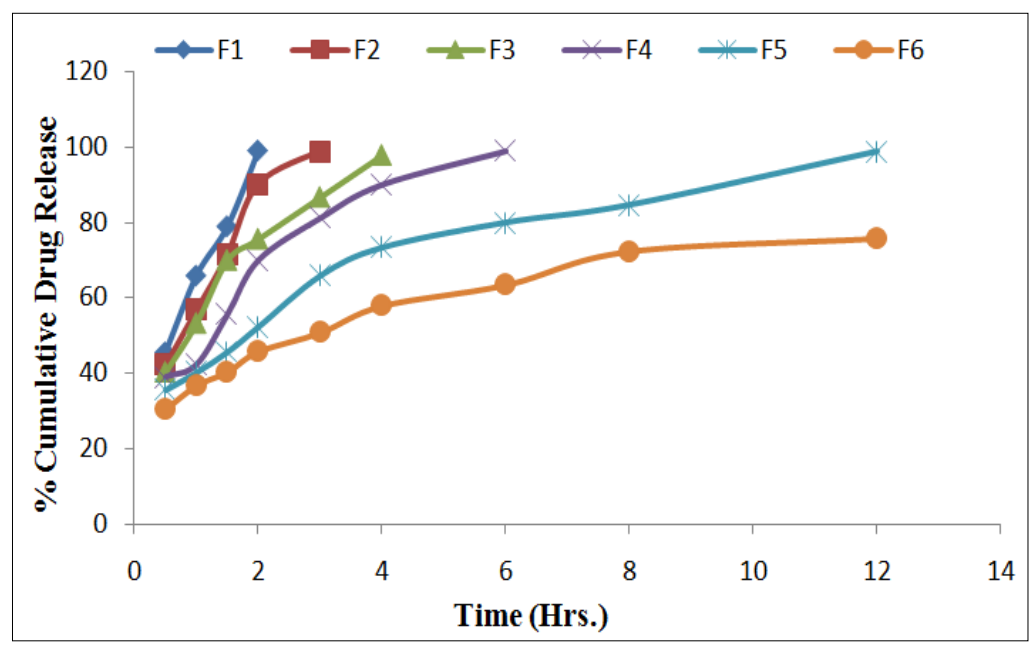

Figure 3: In-vitro drug release study of matrix tablets

Table 6: In-vitro drug release data for optimized formulation F5

\begin{tabular}{|c|c|c|c|c|c|c|}
\hline Time (h) & $\begin{array}{c}\text { Square Root } \\
\text { of Time(h) } \mathbf{1 / 2}\end{array}$ & Log Time & $\begin{array}{c}\text { Cumulative*\% } \\
\text { Drug Release }\end{array}$ & $\begin{array}{c}\text { Log Cumulative } \\
\text { \% Drug Release }\end{array}$ & $\begin{array}{c}\text { Cumulative \% } \\
\text { Drug Remaining }\end{array}$ & $\begin{array}{c}\text { Log Cumulative } \\
\text { \% Drug } \\
\text { Remaining }\end{array}$ \\
\hline 0.5 & 0.707 & -0.301 & 35.56 & 1.551 & 64.44 & 1.809 \\
\hline 1 & 1 & 0 & 40.23 & 1.605 & 59.77 & 1.776 \\
\hline 1.5 & 1.414 & 0.301 & 45.65 & 1.659 & 54.35 & 1.735 \\
\hline 2 & 2 & 0.602 & 52.32 & 1.719 & 47.68 & 1.678 \\
\hline 3 & 2.449 & 0.778 & 65.85 & 1.819 & 26.68 & 1.533 \\
\hline 4 & 2.828 & 0.903 & 73.32 & 1.865 & 20.02 & 1.426 \\
\hline 6 & 3.464 & 1.079 & 79.98 & 1.903 & 15.35 & 1.186 \\
\hline 8 & 0.707 & -0.301 & 84.65 & 1.928 & 1.22 & 0.086 \\
\hline 12 & 1 & 0 & 98.78 & 1.995 & & \\
\hline
\end{tabular}

Table 7: Regression analysis data of glimepiride matrix tablets

\begin{tabular}{|c|c|c|c|c|}
\hline \multirow{2}{*}{ Batch } & Zero Order & First Order & Higuchi & Korsmeyer-Peppas \\
\cline { 2 - 5 } & $\mathbf{r}^{\mathbf{2}}$ & $\mathbf{r}^{\mathbf{2}}$ & $\mathbf{r}^{\mathbf{2}}$ & $\mathbf{r}^{\mathbf{2}}$ \\
\hline F5 & 0.896 & 0.916 & 0.964 & 0.979 \\
\hline
\end{tabular}

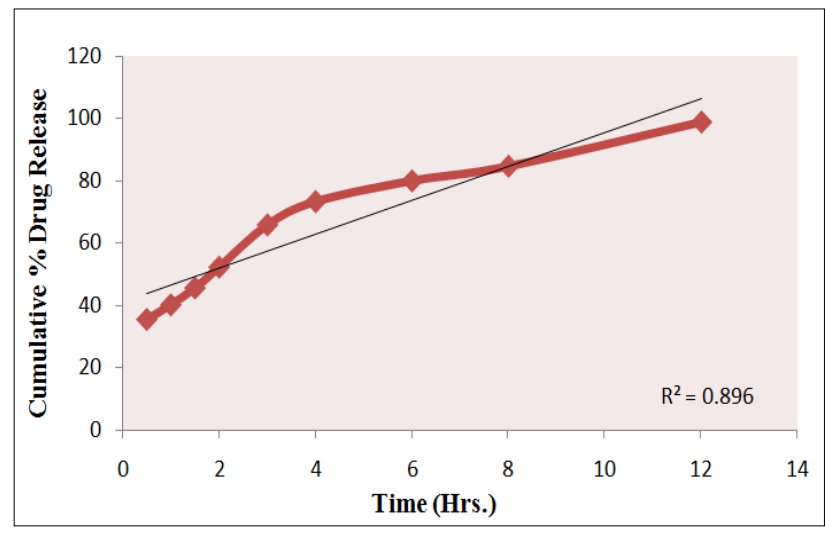

Figure 4: Zero order release Kinetics

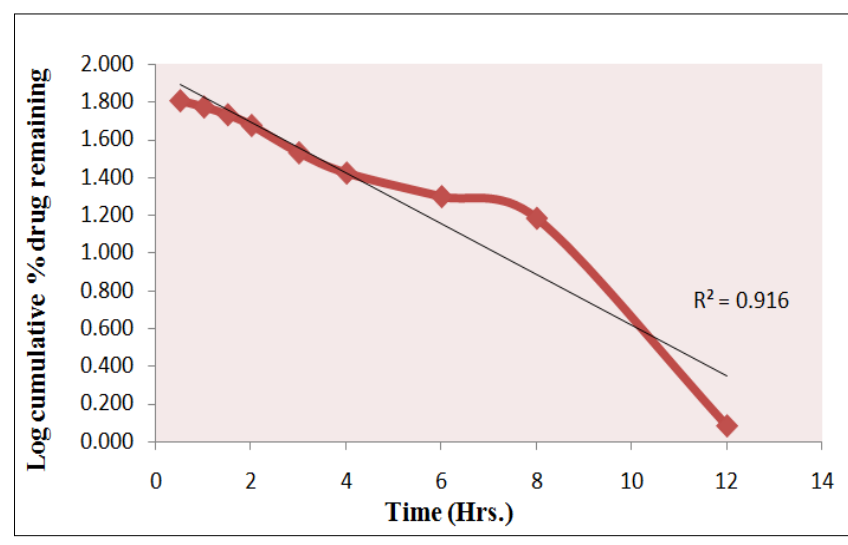

Figure 5: First order release kinetics 


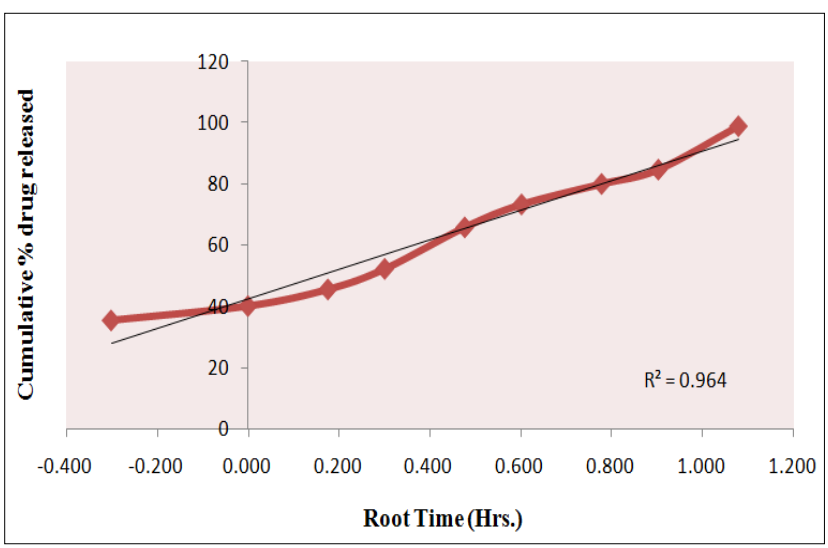

Figure 6: Higuchi release Kinetics

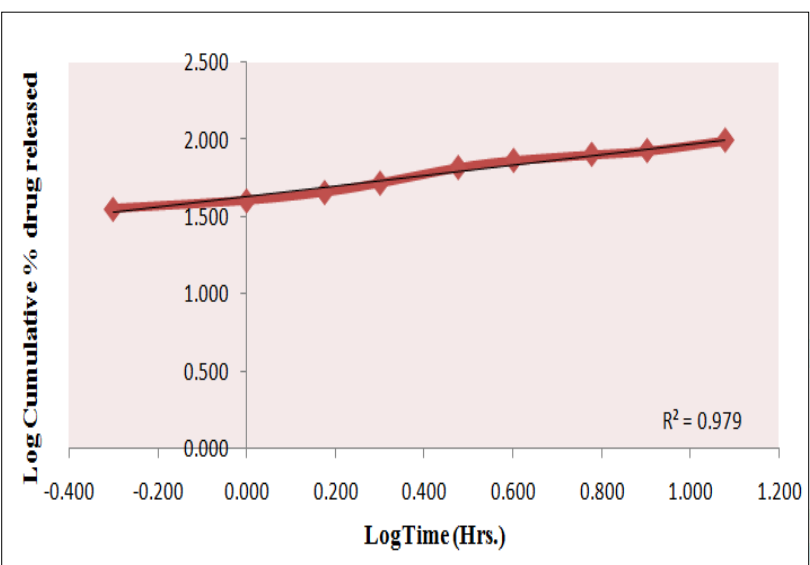

Figure 7:Korsmeyer-Peppas release Kinetics

\section{CONCLUSION}

Direct compression methods can be used alternatively for wet granulation, because it is an easier, simplified and economical method of manufacturing of tablets. A number of research articles are available which are evident that the direct compression is a preferred method of tableting. The present research work was successful in improving the efficacy of glimepiride oral therapy as the drug release was extended for 12 hours thus reducing dosing frequency thereby improving patient compliance. The gastroretentive mucoadhesivematrix tablets of glimepiride were prepared by direct compression method. Kinetic modeling showed that best fit model was the Korsmeyer-Peppas model, with non-Fickian diffusion tending towards zero-order release, indicating that the tablets can be successfully employed as a once daily, oral, controlled-release drug delivery system. The high bioadhesive strength of the tablets increases its gastrointestinal residence time and eventually improves the extent of bioavailability. However, proper balancing between the different levels of polymers is necessary to attain proper bioadhesion.

\section{REFERENCES}

1. Giradkar KP, Channawar MA, Kajale AD, et al. Design, development and in vitro evaluation of bioadhesive dosage form for buccal route. Int J Pharm Res Dev, 2010; 1(6):01-20.

2. Sachin CM, Venkateshwarlu BS, Bhowmik D, Jayakar B. Formulation and evaluation of controlled release mucoadhesive oral tablet of clarithromycin. Der Pharmacia Lettre, 2009; 1(1):83-91.
3. Bagul U, Gujar K, Dhat S, et al. In vitro study of mucoadhesive strength of polymers for mucoadhesive drug delivery systems. Int J Curr Pharm Res, 2009; 1(1):42-46.

4. Gavin P, Thomas PL, David SJ. Mucoadhesive polymeric platforms for controlled drug delivery. Eup J PharmBiopharm, 2009; 505-518.

5. Parthiban KG, Kumar BS, Manivannan R, kumar DS. Once daily gastro retentive mucoadhesive cephalexin monohyrate tablet: Formulation and in-vitro evaluation. Int J Pharm Sci Res, 2010; 1(5):89-98.

6. Kiran T, Shastri N, Ramakrishna S,Sadanandam M. Surface solid dispersion of glimepiride for enhancement of dissolution rate. Int J Pharm Tech Res, 2009; 1:822-831.

7. Ning X, Sun J, Han X, et al. Strategies to improve dissolution and oral absorption of glimepiride tablets: solid dispersion versus micronization techniques. Drug DevInd Pharm, 2011; 37:727-736.

8. Rajpurohit VS, Rakha P, Goyal S, et al. Formulation and characterization of solid dispersions of glimepiride through factorial design. Iran J Pharm Sci.2011; 7:7-16.

9. Pachisia N,Agrawal SS, Formulation, development and evaluation of transdermal drug delivery system of glimepiride. Int J Pharm PharmSci Res. 2012; 1-8.

10. Rani TS, Sujatha S,Veeresham C. Pharmacokinetic and phamacodynamic interaction of curcumin with glimepiride in normal and diabetic rats. PharmacogCommun, 2012; 2:14-21.

11. Pattanayak DP,Dinda SC. Bilayer tablet formulation of metformin hydrochloride and glimepiride: A novel approach to improve therapeutic efficacy. Int J Drug Disc Herb Res, 2011; 1:1-4.

12. Alhalmi A, Altowairi M, Saeed O, et al. Sustained release matrix system: an overview, World Journal of Pharmacy and Pharmaceutical Sciences; 2018; 7(6):1470- 1486.

13. Singh R, Malviya R, Sharma P. Extraction and characterization of tamrind seed polysaccharide as pharmaceutical excipients. Pharmacognosy Journal, 2011; 3(20):17.

14. Abdul HM, Lokeswara BV, Pal N; Formulation and Evaluation of Sustained Release Matrix Tablets of Glimepiride Based on Combination of Hydrophilic and Hydrophobic Polymers; Journal of Applied Pharmaceutical Science; 2012; 2(6):101107.

15. Gupta S, Dev A. Formulation and characterization of mucoadhesive matrix tablet of nizatidine. Asian J Pharm Clin Res, 2018; 11(6):277-283.

16. Sinko PJ. Physical Pharmacy and Pharmaceutical Sciences, Lippincott Williams and Wilkins, 5th Edition, 2006.

17. Chein Y W. Novel drug delivery systems, Marcel Dekker, INC, 2nd edition, 1992, 140 .

18. Liberman HA, Lachman L, Schwartz JB. Pharmaceutical dosage forms: Tablets, 3rd edition, Marcel Dekker, New York, 1990.

19. Hadjiioannou TP, Christian GD, Koupparis MA. VCH Publishers Inc.; New York, USA: 1993. Quantitative calculations in pharmaceutical practice and research.

20. Salsa T, Veiga F, Pina ME. Drug DevInd Pharm. 1997; 23:929 938.

21. Polymers for mucosal delivery-Swelling and mucoadhesive evaluation. Indian Drugs, 2002, 39(5):270-276

22. Shinkar DM, Dhake AS,Setty CM. Drug delivery from the oral cavity: a focus on mucoadhesive buccal drug delivery systems. PDA J Pharm Sci and Tech 2012; 66:466-500.

23. Derle D, Pawar A,Patel J, et al. Formulation and evaluation of buccoadhesive bi-layer tablet of propranolol hydrochloride. International Journal of Pharmacy and Pharmaceutical Sciences, 2009; 1(1):45-50.

24. Brahmankar DM, Jaiswal SB. Biopharmaceutis and Pharmacokinetics: A Tretise,VallabhPrakashan, New Delhi, 1st edition, 2006, 335-357.

25. Costa P, LoboML.Modeling and comparison of dissolution profiles. European Journal of Pharmaceutical Sciences. 2001; 13(2):123-133.

26. Korsemeyer RW, Gurny R, Doelker EM, et al. Mechanism of solute release from porous hydrophilic polymers. Int J Pharm, 1983;15:25-35. 